Original Research Paper

\title{
Literature Review on Machine Reliability in Cellular Manufacturing System
}

\author{
${ }^{1}$ A. Nouri Houshyar, ${ }^{1}$ Z. Leman, ${ }^{2}$ H. Pakzad Moghadam and ${ }^{3}$ R. Sulaiman \\ ${ }^{1}$ Department of Mechanical and Manufacturing Engineering, University Putra Malaysia, Malaysia \\ ${ }^{2}$ Department of Industrial Engineering, University of Tehran, Tehran, Iran \\ ${ }^{3}$ Institute of Visual Informatics, University Kebangsaan Malaysia, Malaysia
}

\author{
Article history \\ Received: 2014-03-30 \\ Revised: 2014-11-24 \\ Accepted: 2014-12-04 \\ Corresponding Author: \\ A. Nouri Houshyar, \\ Department of Mechanical \\ and Manufacturing \\ Engineering, University \\ Putra Malaysia, Malaysia \\ Email: a_nh86@yahoo.com
}

\begin{abstract}
Nowadays, in the global markets companies have to produce highquality product, low cost product in order to be alived in competetive markets. Group technology helps manufacturer to raech this aim. One of the most proper applications of group technology is called Cellular Manufacturing System (CMS). CMS is able to implement in the manufacturing system for overcoming the waeakness of traditional manufacturing system such as Job shop, Flow shop. One of the main challenging issues in CMS is named machine reliability and breakdown. Although, production facilities and machines are improving and becoming more sophisticated, they are not free from deterioration due to the aging which leads to shifting from in-control to out-of-control state for the machines and also breakdown of machines in the planning horizon. This study provides a comprehensive review on literature of machine reliability in cellular manufacturing system. This study made attempts to gather all the researches which have been done on machine reliability in CMS. In fact this issue was considered by the author since, moving from in-control state to out-of-control state and also machine breakdown have effective impacts on the system; therefore, it is essential for manufacturers to consider this subject in their study for preventing the huge wastage of time and cost in the system which will be occurred as results of this phenomena.
\end{abstract}

Keywords: Cellular Manufacturing System, Reliability, Maintenance Planning

\section{Introduction}

In the previous decades, manufacturers faced a lot of challenges because of globalization and high competition in markets. These problems arise from shorting product life cycle, rapid variation in demand of products and also rapid changes in manufacturing technologies. Nowadays, in order to overcome these kind of problems, manufacturers try to select and implement the type of manufacturing system which be able to mid-variety and mid-volume of products. During past decades, manufacturers implemented traditional type of manufacturing system such as flow line and job shops in their company. For instance, as flow line manufacturing system has been showing in Fig. 1, all facilities are arranged based on the operation sequence of each products, hence these system can be suitable for high production rate with a few type of products.

In contrast, the job shop system which has been shown in Fig. 2, facilities will be arranged based on their functions and also similar processes are located together.
This manufacturing sysem responds to the wide variaty of products in a small volumes.

Cellular manufacturing system is an efficent application of group technology which is able to mix both spesifications of flow line and job shop and be responsed to the new requirements of the market and it is able to overcome some of the traditional's weakness. In other words, cellular manufacturing system combines efficiency of flow line with flexibility of job shop. Cellular manufacuring system can be considered as a successful application of group technology which is able to fulfill today's requiremnets (Rafiee et al., 2011).

\section{Reliability in CMS}

Machines are the major components of any manufacturing system, during these decades, although machines are becoming sophisticated and modern day by day, they are not free from deterioration due to usage and aging. Due to usage and aging deterioration, machines shift from in-control to out-control and also the breakdown occur in the system. 


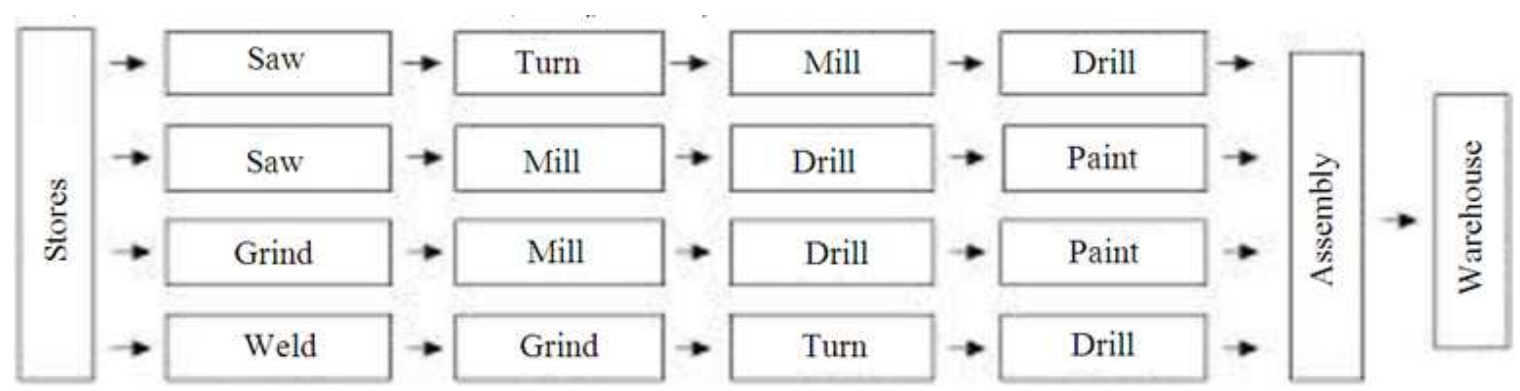

Fig. 1. A flow line layout

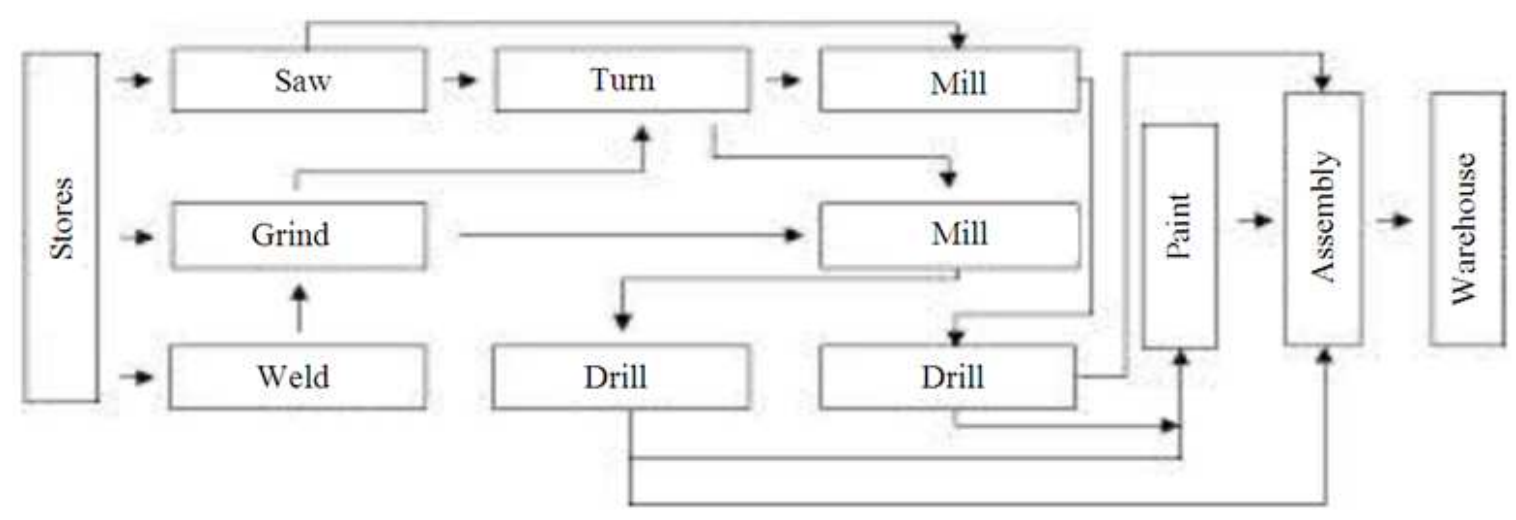

Fig. 2. A job shop layout

Machine breakdown is one of the major problem which effects on due date and optimal cost of system; therefore, concentrating on this issue is so essential. The reliability problem cannot be solved easily unless it is designed and planned specifically (Das, 2008). Most of the previous model in designing CMS considered that machines are $100 \%$ reliable although it is not like that in reality (Das, 2008; Saxena and Jain, 2011). Seifoddini and Djaaemi (2001) expressed that machine reliability has an important impact on performance of CMS. In addition, they proved that impacts of breakdown delays are not limited to the production rate of parts, but it has effect on scheduling and productivity of whole manufacturing operations. Hence, it is crucial to consider reliability and break down of the machines for having an efficient manufacturing system.

Ameli and Arkat (2008) expressed that, reliability can be modeled as machine repair cost or production time delay cost. In addition, for modeling the possibility of failure in machine and system, there is two type of distribution are used which are as follows:

- Exponential distribution

- Weibull distribution

Most of papers in literature applied exponential distribution in order to show the breakdown and failure of machines in the system (Diallo et al., 2001; Lokesh and
Jain, 2010; Savsar, 2000; Yazhau et al., 1995). One of the main weaknesses of exponential distribution is related to disability of this distribution to show the increasing of failure rate with increase in machine age. In other words, with passing years the possibility of happening the failure in the system will be increased but the exponential distribution is unable to show this increscent and considered constant failure rate at all. Since, this distribution has the same behavior during different periods of time for presenting the failure rate without considering the ageing of machines; therefore, to overcome this problem, some researchers applied weibull distribution instead. That is to say, the weibull distribution is able to present breakdown and failure of machines more close to reality and practical situation. In addition, this distribution is able to show increasing of failure rate by considering machine age (Das, 2008).

Since any disruptions or failures in the system leads to stop production process, delay in due date and customer dissatisfaction, therefore, considering reliability, breakdown in the system and having an efficient maintenance plan become important issues during these years and attracts the attention of researchers. Some of the researches are expressed in following section.

Logendran and Talkington (1997) carried out a research which concentrated on performance of CMS with presence of machine breakdown and preventive 
maintenance. Their results revealed that preventive maintenance will improve the reliability in case of increasing the failure rate.

Jeon et al. (1998) proposed a CMS model with regards to machine failure and alternative routings. Their study had a predefined number of machine's breakdown. Moreover, they developed a model in order to reduce waiting cost, early/late finish penalty cost and inventory holding cost.

Diallo et al. (2001) presented an approach for cell formation problem. Their approach was based on changing in process plan to overcome machine breakdown problem. Exponential distribution had been applied for presenting the machine reliability in their research. This model is able to allocate the demand production of parts to specific process until the breakdown happens in the system; then, the process allocation of parts will be changed to get rid of occurred problem.

Kuroda and Tomita (2005) proposed a robust model for designing the cellular-line production system which includes unreliable facilities in cellular manufacturing system. They defined Exponential distribution for times to failure and also repair time in their model. They simulated model and validated it via the numerical experiments.

Das et al. (2007b) proposed a multi-objective mixedinteger programming model for designing the CMS. Their goal were minimizing total system cost and maximizing machine reliability. The proposed approach made attempt to provide the best design for CMS with minimizing the machine failure impacts. In other words, in cellular manufacturing system each process and part is allocated to machines, then each machine assigned to the route with different level of reliability. The aim of this research was to select the most reliable route which has the minimum breakdown and failure by considering the minimum system cost.

In addition, Das et al. (2007a) presented a model for improving the performance of system in cellular manufacturing in terms of machine reliability and resource utilization. They defined preventive maintenance planning for their system in order to increase the performance. In addition, they made attempts to minimize the total maintenance cost and overall probability of machine failures.

Das (2008) proposed two multi-objectives model for solving cell formation problem in CMS. His objectives were minimization of cost and also minimization of failure rate. In the first mathematical model he applied Exponential distribution for presenting the failure rate. Then in the second mathematical model he used Weibull distribution. He proved that the Weibull distribution is more fitted to breakdown of machine in comparison to Exponential distribution. In addition, he proved that applying Weibull distribution leads to better cell configuration.
Moreover, Ameli and Arkat (2008) proposed a mathematical method for calculating the machine breakdown cost. The breakdown cost is gained via dividing the production time by the mean time between the failure and then multiplying this quantity by the machine breakdown cost. Plus, in their research they made attempt to minimize the sum of intra-cell movement cost and machine break down cost in order to solve the cell formation problem in cellular manufacturing system.

Elleuch et al. (2008) proposed a solution for overcoming the negative effects of machine breakdown in cellular manufacturing system. Their solution was based on principle of virtual cell and also it noted to inter-cell material transfer for decreasing the negative impacts of machine breakdown, control and improve the system efficiency under the breakdown situation.

Plus, Ahkioon et al. (2009) investigated on designing the CMS. They considered machine procurement, production planning, system reconfiguration and routing flexibility in their research. An important aspect of their research is related to routing flexibility. Due to machine breakdown which may occur in the system, their work allows to CMS to operate in a continuous manner by choosing another route. Considering rout flexibility was a method in their research for overcoming the breakdown problem.

Plus, Lokesh and Jain (2010) proposed a mixedinteger non-linear programming model for dynamic cellular manufacturing system. Their model considered some important manufacturing attributes like: Machine breakdown effects(machine repair and production time loss cost), production planning (inventory holding cost, internal production cost and outsourcing cost), batch size for inter-cell and intra-cell travel, sequence of operation, machine capacity, work load balancing, machine procurement, cell reconfiguration. They proposed a Hybrid Hierarchical Genetic Algorithm (HHGA) for solving the model. Their result revealed that proposed HHGA needs less computational time than Lingo-based solution approach.

Beside, Rafiee et al. (2011) proposed a mathematical model in order to solve the cell formation problem in dynamic cellular manufacturing system with regard to inventory lot sizing. Their objectives were cost minimization of: Procurement, reconfiguration, set up, operation, inter and intra-cell, sub-contracting, inventory holding, corrective and preventive maintenance. Their research novelty was that they considered the maintenance planning cost in their model for controlling the machine breakdown effects. Particle Swarm Optimization (PSO) was applied as their method for solving the model.

Moreover, Chung et al. (2011) presented an algorithm for solving the cell formation problem in CMS with regards to alternative routings and machine reliability. They applied Tabu search method for their 
research. At first their algorithm generated solutions then the solutions were improved by a tube search algorithm combining the mutation operator and an effective neighborhood solution searching mechanism.

In addition, Fardis et al. (2013) proposed a mathematical model for solving the cell formation problem in cellular manufacturing system. They defined the parameters of arrival rate of parts to the cell and machine service rate via the Exponential distribution. Plus, they defined the average waiting time of parts behind each machine as a solution for overcoming the unscheduled disruption problem which may happen in the system. They solved the proposed model via the Cplex solver of GAMS.

Although machine reliability has an importance role in manufacturing system, it gained a few attentions to itself (Das, 2008). In other words, in a CMS design it is crucial to take into the account the issue of machine reliability, since, it has important impacts on cell formations and also production capacity in each periods (Das, 2008). Therefore, concentrating on maintenance planning for controlling and preventing unscheduled disruption in the system is essential.

\section{Conclusion}

This study addressed the issue of machine reliability and breakdown in the cellular manufacturing system. Put differently, this study reviewed all researches which have been done in this issue. In fact, this study can help the other researchers who are interested to do research in Cellular manufacturing system and its related topics by considering the machine reliability. In fact, since this topic has an important impact of the manufactruing system, the author recommends the other researchers to consider it in their study for reaching the applicable system.

\section{Author's Contributions}

All authors equally contributed in this work.

\section{Ethics}

This article is original and contains unpublished material. The corresponding author confirms that all of the other authors have read and approved the manuscript and no ethical issues involved.

\section{References}

Ahkioon, S., A.A. Bulgak and T. Bektas, 2009. Cellular manufacturing systems design with routing flexibility, machine procurement, production planning and dynamic system reconfiguration. Int. J. Product. Res., 47: 1573-1600.

DOI: $10.1080 / 00207540701581809$
Ameli, M.S. and J. Arkat, 2008. Cell formation with alternative process routing and machine relaibility consideration. Int. J. Adv. Manufac. Technol., 35: 761-768. DOI: 10.1007/s00170-006-0753-6

Chung, S., T. Wu and C. Chang, 2011. An efficient tabu search algorithm to the cell formation problem with alternative routings and machine reliability considerations. Comput. Industrial Eng., 60: 7-15. DOI: $10.1016 /$ j.cie.2010.08.016

Das, K., 2008. A comparative study of exponential distribution Vs Weibull distribution in machine reliability analysis in a CMS design. Comput. Industrial Eng., 54: 12-33. DOI: $10.1016 /$ j.cie.2007.06.030

Das, K., R.S. Lashkari and S. Sengupta, 2007a. Machine reliability and preventive maintenance planning for cellular manufacturing systems. Eur. J. Operational Res., 183: 162-180. DOI: 10.1016/j.ejor.2006.09.079

Das, K., R.S. Lashkari and S. Sengupta, 2007b. Reliability consideration in the design and analysis of cellular manufacturing systems. Int. J. Product. Econ., 105: 243-262. DOI: 10.1016/j.ijpe.2006.04.015

Diallo, M., H. Pierreval and A. Quilliot, 2001. Manufacturing cells design with flexible routing capability in presence of unreliable machines. Int. J. Product. Econ., 74: 175-182. DOI: 10.1016/S0925-5273(01)00124-4

Elleuch, M., H. Bacha, F. Masmoudi and A. Maalej, 2008. Analysis of cellular manufacturing systems in the presence of machine breakdowns: Effects of intercellular transfer. J. Manufactur. Technol. Manage., 19: 235-252. DOI: $10.1108 / 17410380810847936$

Fardis, F., A. Zandi and V. Ghezavati, 2013. Stochastic extension of cellular manufacturing systems: A queuing-based analysis. Int. J. Industrial Eng., 9: 920. DOI: $10.1186 / 2251-712 X-9-20$

Jeon, G., H.R. Leep and H.R. Parsei, 1998. Cellular manufacturing system based on new similarity coefficient which considers alternative routes during machine failure. Comput. Industrial Eng., 34: 21-36. DOI: 10.1016/S0360-8352(97)00148-4

Kuroda, M. and T. Tomita, 2005. Robust design of a cellular-line production system with unreliable facilities. Comput. Industrial Eng., 48: 537-551. DOI: 1016/j.cie.2004.03.004

Logendran, R. and D. Talkington, 1997. Analysis of cellular and functional manufacturing system in the presence of machine breakdown. Int. J. Product. Econ., 53: 239-256. DOI: 10.1016/S0925-5273(97)00100-X

Lokesh, K. and P.K. Jain, 2010. Dynamic cellular manufacturing systems design-A comprehensive model and HHGA. Adv. Product. Eng. Manage., 5: 151-162. 
Rafiee, K., M. Rabbani, H. Rafiei and A. Rahimi-Vahed, 2011. A new approach towards integrated cell formation and inventory lot sizing in an unreliable cellular manufacturing system. Applied Math. Mode., 35: 1810-1819.

DOI: $10.1016 /$ j.apm.2010.10.011

Savsar, M., 2000. Reliability analysis of a flexible manufacturing cell. Reliab. Eng. Syst. Safety, 67: 147-152. DOI: 10.1016/S0951-8320(99)00056-3

Saxena, L. and P. Jain, 2011. Dynamic cellular manufacturing systems design-a comprehensive model. Int. J. Adv. Manufactur. Technol., 53: 11-34. DOI: $10.1007 / \mathrm{s} 00170-010-2842-9$
Seifoddini, S. and M. Djassemi, 2001. The effect of reliability consideration on the application of quality index. Comput. Industrial Eng., 40: 65-77. DOI: $10.1016 / \mathrm{S} 0360-8352(00) 00072-3$

Yazhau, J., W. Molin and J. Zhixin, 1995. Probability failures of machining center failures. Reliab. Eng. Syst. Safety, 50: 121-125.

DOI: 10.1016/0951-8320(95)00070-I 